\title{
Microstructure Evolutions and Properties of Al-Cu Alloy Joint in the Pulsed Power Ultrasonic-Assisted GMAW
}

\author{
Chao Chen ${ }^{1} \cdot$ Chenglei Fan ${ }^{1} \cdot$ Zeng Liu ${ }^{1} \cdot$ Xiaoyu Cai $^{1} \cdot$ Sanbao Lin $^{1} \cdot$ Yimin Zhuo ${ }^{1}$
}

Received: 28 February 2020 / Revised: 14 March 2020 / Published online: 13 May 2020

(c) The Chinese Society for Metals (CSM) and Springer-Verlag GmbH Germany, part of Springer Nature 2020

\begin{abstract}
The pulsed power ultrasonic-assisted gas metal arc welding (PU-GMAW) is a new development hybrid welding method. The influences of the pulsed power ultrasonic on the microstructure evolution of the welded joint of $\mathrm{Al}-\mathrm{Cu}$ alloy were investigated by using scanning electron microscopy, transmission electron microscope and electron back scattering diffraction. The results showed that the efficient heat input in the PU-GMAW was increased by above $100 \%$ compared with the traditional GMAW. The grain and eutectic of the PU-GMAW weld seam were refined compared with that of the GMAW. Cavitation and acoustic streaming induced the dendrite fragmentation $(\alpha-\mathrm{Al})$ and heterogeneous nucleation, which were the main reasons for the grain refinement. The microhardness of the PU-GMAW welded joint was improved compared with that of the GMAW owing to the change of the eutectic and grain.
\end{abstract}

Keywords Pulsed power ultrasonic $\cdot$ Al-Cu alloy $\cdot$ Microstructure $\cdot$ Cavitation $\cdot$ Acoustic streaming

\section{Introduction}

Gas metal arc welding (GMAW) is usually employed to weld metal materials, such as steel, aluminum alloy and titanium alloy due to its high efficiency and low cost [1-3]. The insufficiencies of the GMAW, such as the welding spatter and low arc energy, will influence the quality of welded joints [4]. Multitudinous hybrid methods were presented to improve the GMAW quality, such as laser GMAW [5-7], variable polarity plasma arc(VPPA)-GMAW [8, 9], tungsten inert gas welding (TIG) GMAW [10, 11] and ultrasonic-assisted GMAW [12-14]. These methods usually can enhance the stability of the welding process, increase the effective heat input, and so on. In the laser GMAW hybrid welding of copper, Zhang et al. [6] indicated that the efficiency of hybrid welding process is increased two times compared with that of the conventional GMAW. The higher quality of the welded joint was obtained by the hybrid welding process. In the VPPA-GMAW of aluminum alloy, the weld penetration

Available online at http://link.springer.com/journal/40195.

Chenglei Fan

fclwh@hit.edu.cn

1 State Key Laboratory of Advanced Welding and Joining, Harbin Institute of Technology, Harbin 150001, China and droplet transfer were improved compared with that of the GMAW, as reported by Han et al. [9]. It can be seen that all these hybrid welding methods are directly combined by two kinds of welding heat sources, which makes the equipments and the control of welding process be complicated. Ultrasonic-assisted GMAW (U-GMAW) is a new kind of hybrid welding method, the welding arc is compressed by ultrasonic and becomes a high energy density welding heat source, which caused the increase in the weld penetration and width $[12,13]$. Under the action of ultrasound, the droplet transition period and droplet size also decreased [12]. Generally, during the U-GMAW process, the ultrasonic works in continuous mode. Recently, a new method of pulsed ultrasonic-assisted GMAW (PU-GMAW) was proposed $[15,16]$. Compared with continuous ultrasonic, the effect of pulsed ultrasonic on arc and droplet is more significant. In addition, under the action of pulsed ultrasound, the oscillation of molten pool is more significant, which means that the effect of pulsed ultrasound on the molten pool is more prominent [17].

During the metal solidification process, if the ultrasonic was added, the refined microstructure could be obtained because of the cavitation and acoustic streaming [18-20]. Grain refinement was also achieved by the action of ultrasonic vibration which was applied to the base metal in gastungsten arc welding of aluminum alloy and magnesium 
alloy [21]. It is different from fixing the ultrasonic radiation end on the welding base metal, the ultrasonic standing wave field and the welding torch were coaxial compound in PU-GMAW, as shown in Fig. 1. Unlike the arc shape and droplet transfer [16], there are few researches focusing on the microstructure of welded joints. In this work, 2A14 aluminum alloy was welded by the PU-GMAW. The grain shape, eutectic and phase distribution, and the properties were researched. The mechanism of ultrasonic wave on the evolution of weld structure was discussed.

\section{Experimental}

2 A14 Al alloy plate with the dimension of $200 \mathrm{~mm} \times 100 \mathrm{~mm} \times 8 \mathrm{~mm}$ was selected as the base metal with the following chemical composition (wt\%): $\mathrm{Cu} 4.48$, Mg 1.68, Si 1.24, Zr 0.81, Mn 0.59, Fe 0.43, V 0.29, Ti 0.15 and balance Al. The welding wire of ER2319 with the diameter of $1.2 \mathrm{~mm}$ was employed with the following chemical composition (wt\%): $\mathrm{Cu} 4.43, \mathrm{Mg} \mathrm{0.91,} \mathrm{Si} \mathrm{0.62,}$ $\mathrm{Zr} \mathrm{0.29,} \mathrm{Mn} \mathrm{0.70,} \mathrm{V} \mathrm{0.33,} \mathrm{Ti} \mathrm{0.55,} \mathrm{Zn} 0.26$ and balance Al. Figure 1 shows the schematic of the PU-GMAW process, and its working principle please refer to Ref. [22]. The welding power source is Kemppi ProMIG-450 welder, and the ultrasonic power source is UGX202D. The ultrasonic wave frequency of $20 \mathrm{kHz}$ was used. The pulsed frequency of the ultrasonic is $50 \mathrm{~Hz}$, and the duty cycle is $50 \%$. The ultrasonic radiator height of $20 \mathrm{~mm}$ was selected, which was the distance between the radiator and base metal. The welding speed $(4 \mathrm{~mm})$, welding voltage $(29 \mathrm{~V})$ and shielding gas flow (20 L/min) were kept constant. Pure argon (99.99\%) with the flow rate of $15 \mathrm{~L} / \mathrm{min}$ was used as the shielding gas. The wire feeding speed was changed from $6 \mathrm{~m} / \mathrm{min}$ to $8 \mathrm{~m} / \mathrm{min}$.
After welding, the samples with the dimension of $20 \mathrm{~mm} \times 10 \mathrm{~mm} \times 8 \mathrm{~mm}$ were cut from each weld bead, as shown in Fig. 2. The polished samples were etched with the Keller solution ( $1 \mathrm{~mL} \mathrm{HF}, 1.5 \mathrm{~mL} \mathrm{HCl}, 2.5 \mathrm{~mL} \mathrm{HNO}_{3}$, $95 \mathrm{~mL} \mathrm{H}_{2} \mathrm{O}$ ). The macrostructure of the welded joints was observed by the optical microscopy (OM). The microstructure was observed by the scanning electron microscopy (SEM), transmission electron microscope (TEM) and electron back scattering diffraction (EBSD). The microhardness of the welded joints was measured under $200 \mathrm{~g}$ load and $10 \mathrm{~s}$ load time.

\section{Results and Discussion}

\subsection{Weld Macrostructure}

A change rate of the geometry parameters of the weld cross section $(\eta)$ was used to evaluate the difference between the GMAW and PU-GMAW, which is defined as Eq. (1).

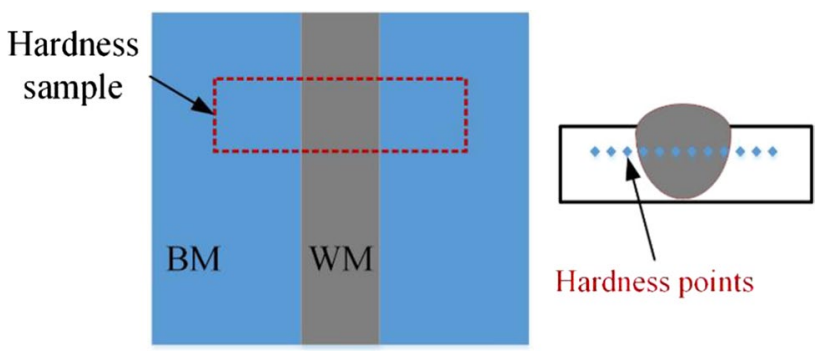

Fig. 2 Location of the hardness samples

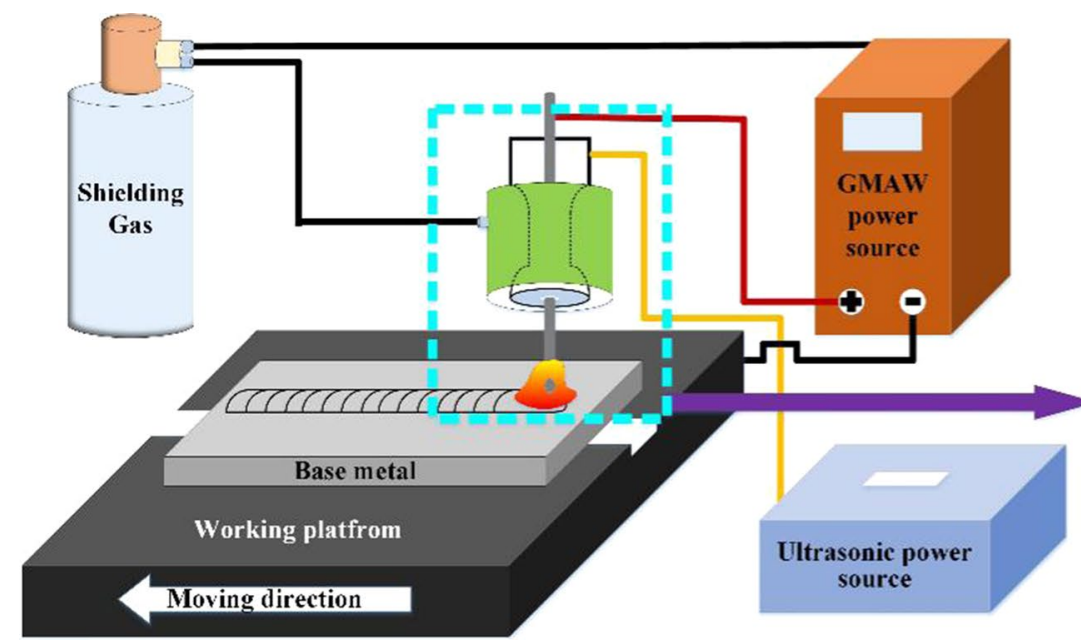

Fig. 1 Schematic of the PU-GMAW process

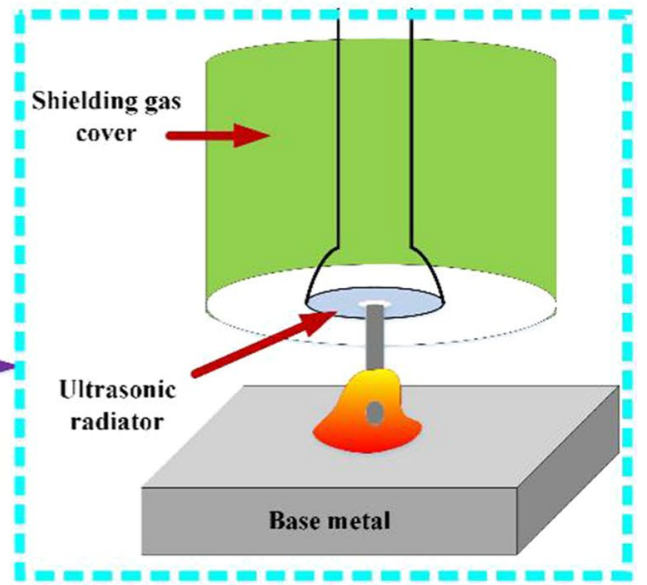


$\eta=\frac{A_{\mathrm{PU}-\mathrm{GMAW}}-A_{\mathrm{GMAW}}}{A_{\mathrm{GMAW}}} \times 100 \%$

where $A_{\text {PU-GMAW }}$ is the weld cross section of PU-GMAW, $A_{\text {GMAW }}$ is the weld cross section of GMAW. The weld cross sections with the different wire feeding speeds are shown in Fig. 3. The weld width in the PU-GMAW is only increased by about $11.2 \%$ compared with that of the GMAW when the wire feeding speed of $6 \mathrm{~m} / \mathrm{min}$ is used, as shown in Fig. 3a. However, the weld penetration and weld area of the PUGMAW are increased to above 1 time compared with that of the GMAW. Efficient heat input is increased obviously by using the PU-GMAW. When the wire feeding speed is increased to $7 \mathrm{~m} / \mathrm{min}$, the full penetration of aluminum alloy with a thickness of $8 \mathrm{~mm}$ is obtained in the PU-GMAW, which is increased by $154.8 \%$ compared with the GMAW. Compared with the penetration and area of the weld, the improvement of the weld width is not obvious in the PUGMAW. When the speed is increased to $8 \mathrm{~m} / \mathrm{min}$, it can be found that the effect of PU-GMAW on the weld cross section is similar under the different wire feeding speed.
Figure 4 shows the width of the heat affect zone (HAZ) with the different processes. The HAZ width in the GMAW is about $230 \mu \mathrm{m}$, which reduced by about $30 \mu \mathrm{m}$ compared with that of the PU-GMAW when the wire feeding speed of $6 \mathrm{~m} / \mathrm{min}$ is used. The HAZ widths in the PU-GMAW are about $130 \mu \mathrm{m}$ and $230 \mu \mathrm{m}$, respectively, when the wire feeding speed of $7 \mathrm{~m} / \mathrm{min}$ and $8 \mathrm{~m} / \mathrm{min}$ are used.

\subsection{Observation of the Microstructure by SEM}

Figure 5 shows the distribution and shape of the eutectic phase with the different weld seams when the wire feeding speed of $6 \mathrm{~m} / \mathrm{min}$ was employed. The eutectic phase of the $\mathrm{Al}-\mathrm{Cu}$ alloy mainly consists of $\alpha-\mathrm{Al}+\theta-\mathrm{Al}_{2} \mathrm{Cu}$, which is the white particle [23]. The eutectic phase of the GMAW weld bead is shown in Fig. 5a. The morphology of the eutectic phase in the different zone is different obviously. The blocky eutectic phase is found in the base metal (Fig. 5a-1 and c). In the HAZ, the eutectic phase is consisted of the line-like eutectic phase and the blocky eutectic phase, as shown in f Fig. 5a-2. In the weld metal, the blocky eutectic phase
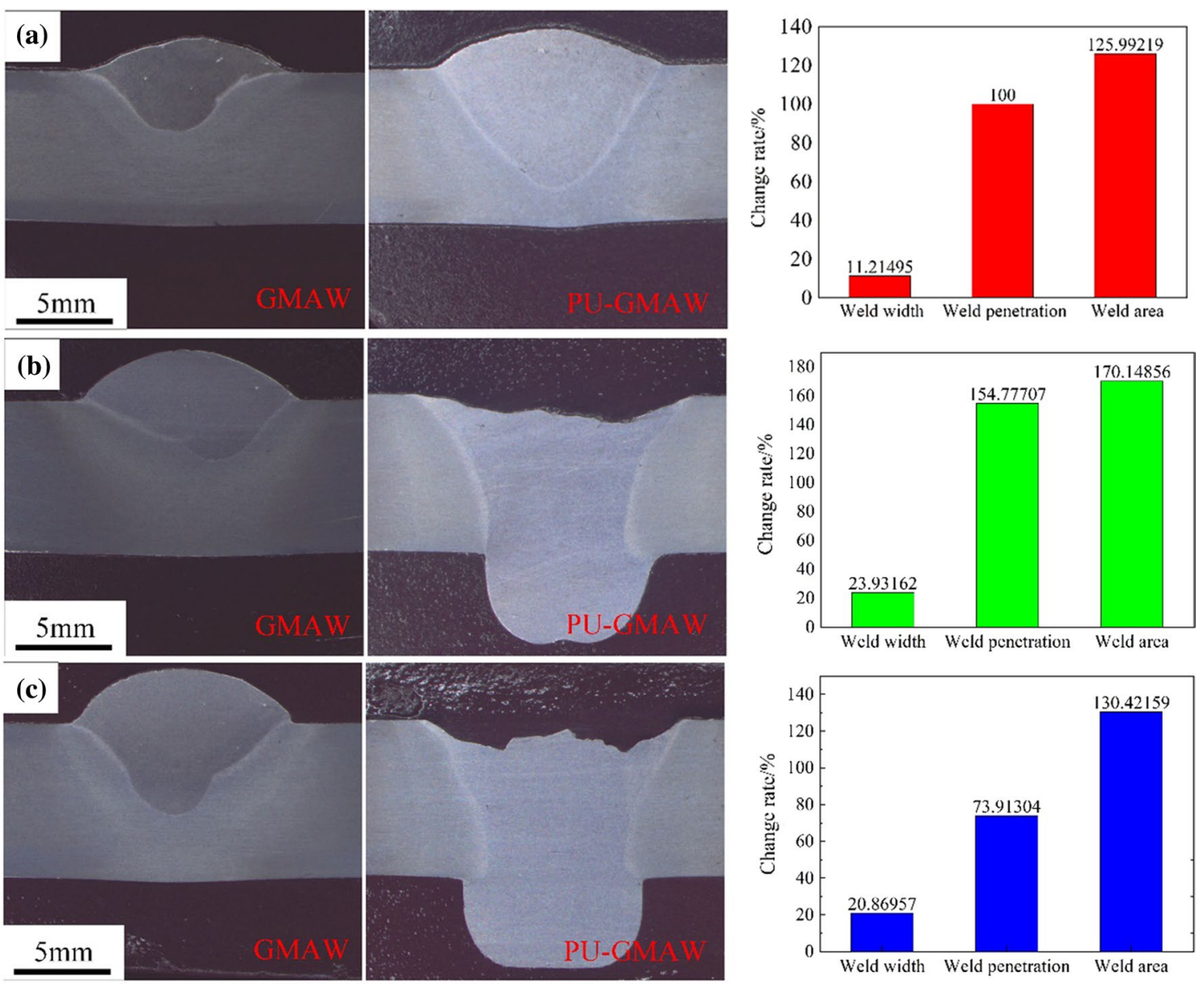

Fig. 3 Weld cross section in the different welding processes: a $6 \mathrm{~m} / \mathrm{min}, \mathbf{b} 7 \mathrm{~m} / \mathrm{min}$, and c $8 \mathrm{~m} / \mathrm{min}$ 


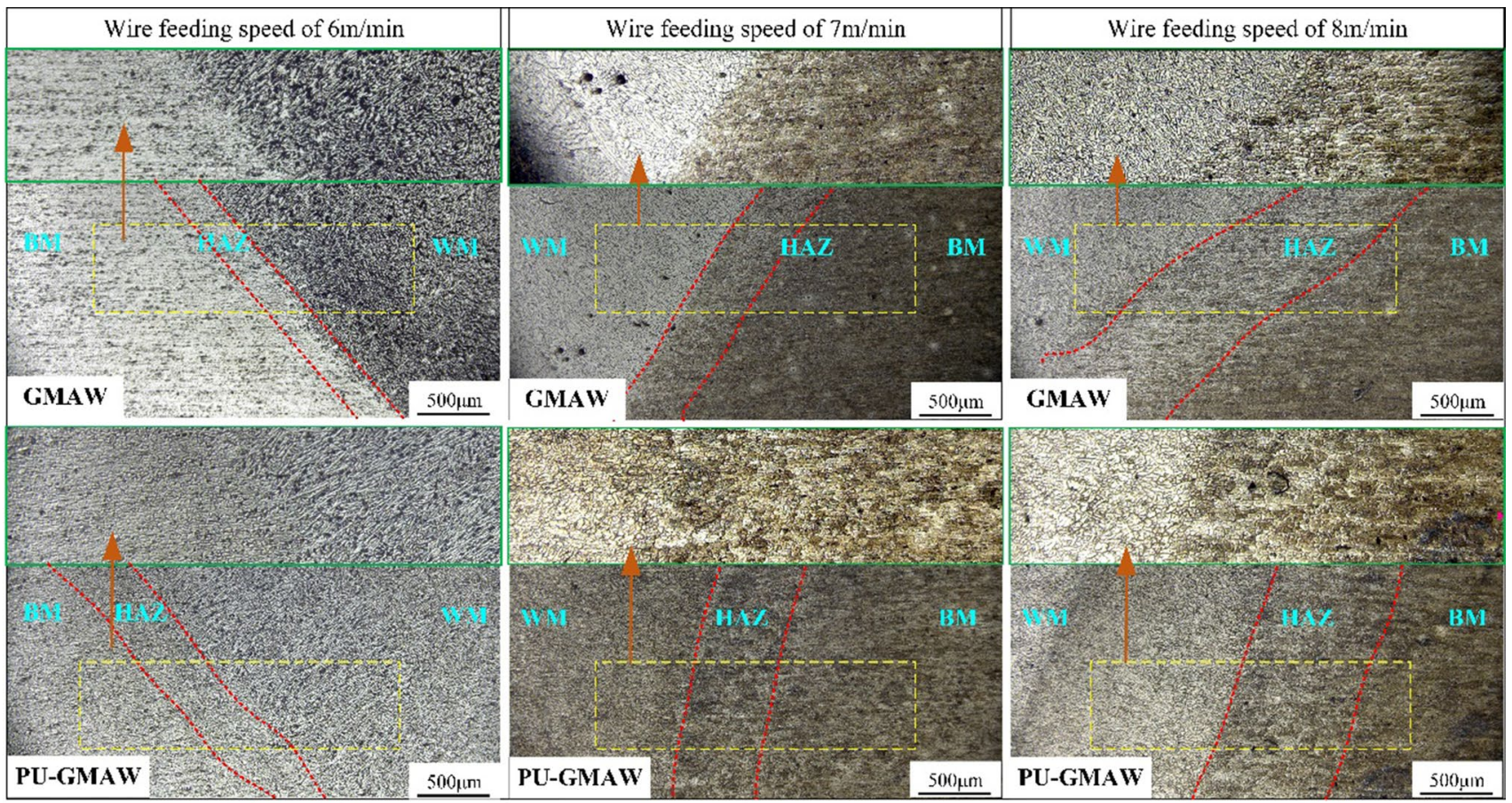

Fig. 4 Heat affect zone widths

is disappeared completely, and only the line-like eutectic phase is observed, as shown in Fig. 5a-3. Figure 5b shows the eutectic phase of the PU-GMAW weld seam. Compared with the GMAW, a new morphology of the eutectic phase, the coil-like eutectic phase, was found near the right side of the fusion line in the PU-GMAW. The size of the coillike eutectic phase is about $30 \mu \mathrm{m}$. The size of the line-like eutectic phase is more than $100 \mu \mathrm{m}$. It can be found that near the fusion line, the size of the eutectic phase of the PU-GMAW is reduced compared with that of the GMAW. The EDS results in the points A and B are shown in Fig. 5d, e, separately. The elements of the eutectic phase are mainly composed of $\mathrm{Al}$ and $\mathrm{Cu}$ (their atomic ratio is 2:1). Therefore, the eutectic phase can be determined as $\mathrm{Al}_{2} \mathrm{Cu}$.

\subsection{Observation of the Microstructure by TEM}

Distribution and morphology of the precipitated phase are observed by TEM, as shown in Fig. 6 . The wire feeding speed of $6 \mathrm{~m} / \mathrm{min}$ was used in the section. The images of TEM in the three locations of base metal are shown in Fig. 6a. The needle-like precipitated phases are evenly distributed at each location, which are identified as $\theta^{\prime}-\mathrm{Al}_{2} \mathrm{Cu}$ [24]. The TEM images of weld metal in the GMAW and PU-GMAW are shown in Fig. 6b, c, respectively. A comparison of the two weld metal indicated that they have the same distribution in the precipitated phase. Some locations do not have the precipitated phase, as shown in Fig. 6b-1. Some locations have the precipitated phase, as shown in Fig. 6b-2. In the weld metal, the distribution of the precipitated phases is not uniform.

\subsection{Observation of the Microstructure by EBSD}

The wire feeding speed of $6 \mathrm{~m} / \mathrm{min}$ was used in the section. The images of EBSD near the fusion line are shown in Fig. 7. Figure 7a shows the images of EBSD near the fusion line in the GMAW. The grain shape includes equiaxed grain and columnar crystal near the fusion line, as shown in Fig. 7a-1. The maximum grain size is greater than $180 \mu \mathrm{m}$, as shown in Fig. 7a-2. The grain orientation and pole figure are shown in Fig. 7a-3 and a-4, respectively. The maxintensity of texture is 3.793 . The grain orientation is not obvious. The equiaxed grain and columnar crystal are also observed near the fusion line in the PU-GMAW (Fig. 7b1). However, the growth directions of the columnar crystal of the PU-GMAW are changed compared with that of the GMAW. As shown in Fig. 7b-2, the maximum grain size in the PU-GMAW is reduced by around $20 \mu \mathrm{m}$ compared with that of the GMAW. The grain orientation is not significant. The max-intensity of texture is 2.761 (Fig. 7b-4), which is reduced by about 1 compared with that of the GMAW.

Figure 8 shows the results of EBSD in the weld center. As shown in Fig. 8a-1 and a-2, the equiaxed grains are found in the GMAW. The maximum equiaxed grain size is greater than $220 \mu \mathrm{m}$. The maximum grain size is about $190 \mu \mathrm{m}$ in 

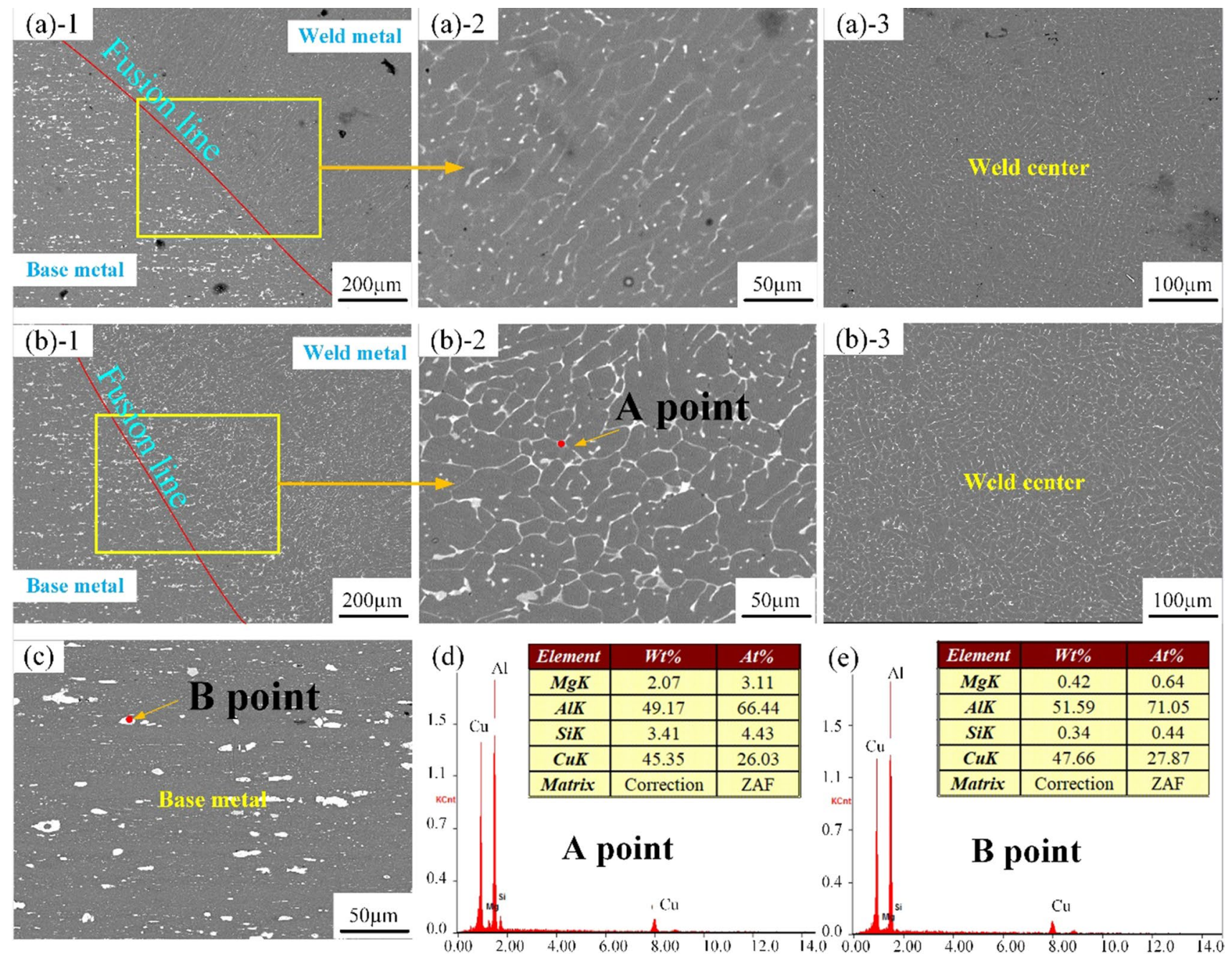

Fig. 5 Distribution and morphology of the eutectic phase: a GMAW, b PU-GMAW, $\mathbf{c}$ base metal, $\mathbf{d}$ EDS of A point, and e EDS of B point

the PU-GMAW, which is reduced obviously compared with that of the GMAW. From the grain orientation and pole figures, it can be found that the max-intensity of texture in the GMAW is 6.194 (Fig. 8a-4), which is increased by 2.6 compared with that of the PU-GMAW (Fig. 8b-4).

\subsection{Distribution of the Microhardness}

In this section, the wire feeding speed of $6 \mathrm{~m} / \mathrm{min}$ was used. Figure 9 shows the distribution of the microhardness of the weld bead in the different welding processes. The black point expresses the microhardness of the GMAW weld bead. The red point expresses the microhardness of the weld bead of the PU-GMAW. The microhardness of the PU-GMAW in the weld center is slightly larger than that of the GMAW. However, near the right of the HAZ, the microhardness in the PU-GMAW is increased by about $20 \mathrm{HV}$ compared with that of the GMAW. The hardness indentation size in the A point was reduced by around $5 \mu \mathrm{m}$ compared with that of the B point.

\subsection{Discussion}

\subsubsection{Effect of Ultrasonic on weld Macrostructure}

During the PU-GMAW, the weld penetration and weld area were improved remarkably. Figure 10 shows the schematic illustration of the effects of the pulsed power ultrasonic on the weld macrostructure. The main reason of the weld appearance improvement is that ultrasonic increases arc energy and arc pressure $[25,26]$.

The literature [27] has reported that during the ultrasonic-assisted arc welding, an ultrasonic standing wave field was produced in the arc burning space. Under the action of the standing wave field, the width and length of the arc were decreased. The acoustic radiation force $\left(F_{\mathrm{a}}\right)$ was the 

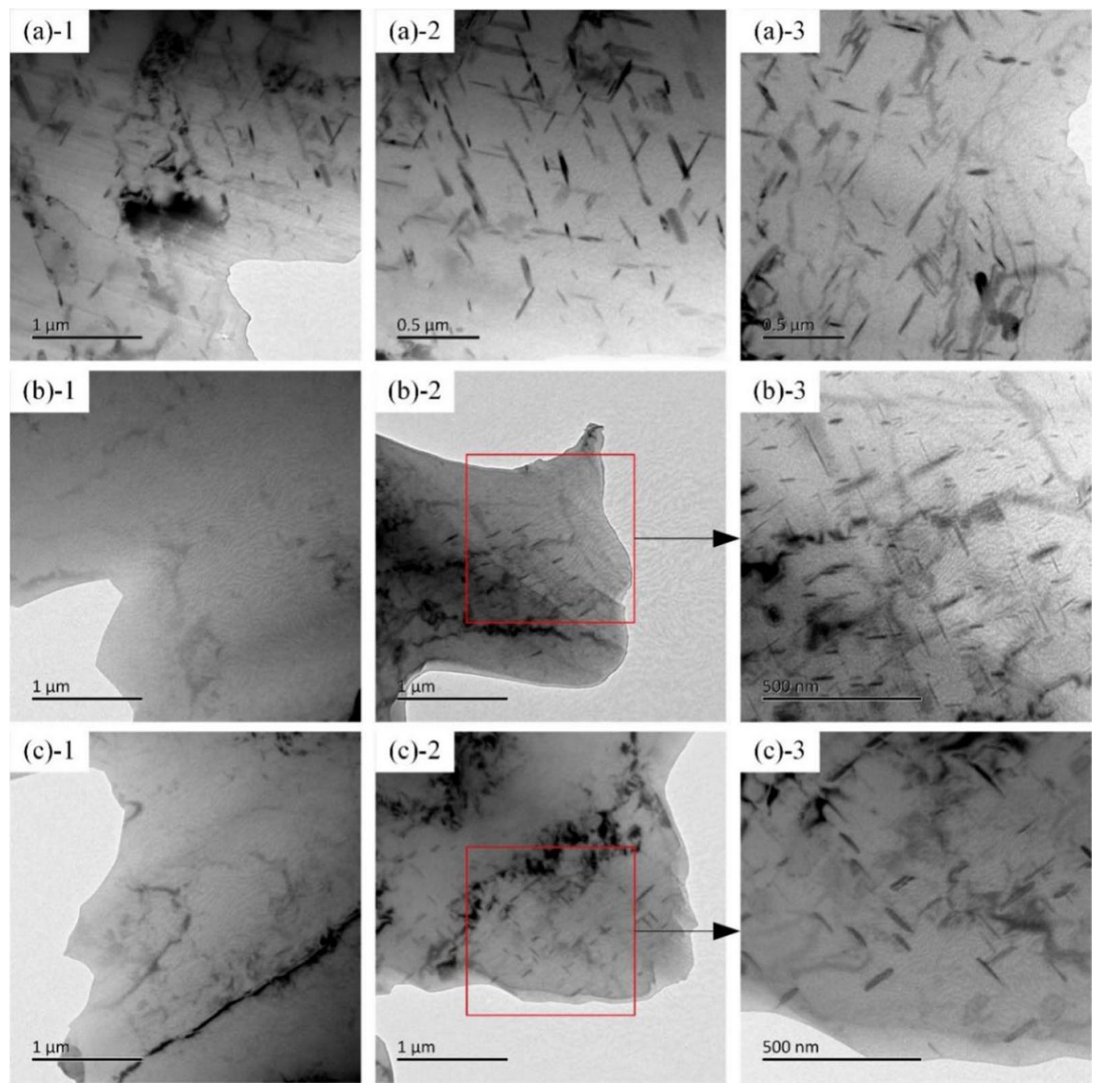

Fig. 6 Distribution and morphology of the precipitated phase: a base metal, b GMAW weld metal, and $\mathbf{c}$ PU-GMAW weld metal

fundamental cause of the change of arc shape, which is defined as Eq. (2) [28].

$F_{\mathrm{a}}=-\operatorname{grad}\left(U_{0}\right)$

The time average potential $\left(U_{0}\right)$ is defined as follows:

$U_{0}=2 \pi R_{\mathrm{s}}^{3}\left[\frac{\bar{p}_{\text {in }}^{2}}{3 \rho_{0} c^{2}} f_{1}-\frac{\rho_{0} \bar{v}_{\text {in }}^{2}}{2} f_{2}\right]$

where $R_{\mathrm{S}}$ is the droplet dimension, $\bar{p}_{\text {in }}^{2}$ is the mean square deviation of the acoustic pressure, $\rho_{0}$ is the density of the shielding gas; the $c$ is the sound velocity in the shielding gas, $\bar{\vartheta}_{\text {in }}^{2}$ is the mean square deviation of the vibration speed, $f_{1}=1-\rho c^{2} / \rho_{\mathrm{s}} c_{\mathrm{s}}^{2}, f_{2}=2\left(\rho_{\mathrm{s}}-\rho\right) /\left(2 \rho_{\mathrm{s}+} \rho\right), \rho_{\mathrm{s}}$ is the ultrasonic radiator density, $c_{\mathrm{s}}$ is the sound velocity in the ultrasonic radiator. The collision frequency of the plasma particles was improved under the action of the ultrasonic. The arc heat dissipation increased. According to the principle of the minimum voltage, the process would cause the arc compression. The geometry parameters of the weld bead must be increased when the arc energy was enhanced. However, the HAZ width in the PU-GMAW was slightly increased due to the increase in arc energy, as shown in Fig. 4. The ultrasonic could increase the arc pressure [25], and thus increasing the weld penetration. It can be summarized that the increase in arc energy and arc pressure originated from ultrasonic had a significant impact on the improvement of the weld macrostructure.

\subsubsection{Effect of Ultrasonic on Weld Microstructure}

Cavitation-induced dendrite fragmentation and cavitationenhanced heterogeneous nucleation are the main influence mechanisms of ultrasonic on the microstructure evolution during the conventional ultrasonic assistance solidification process [29]. Figure 11 shows the schematic illustration 

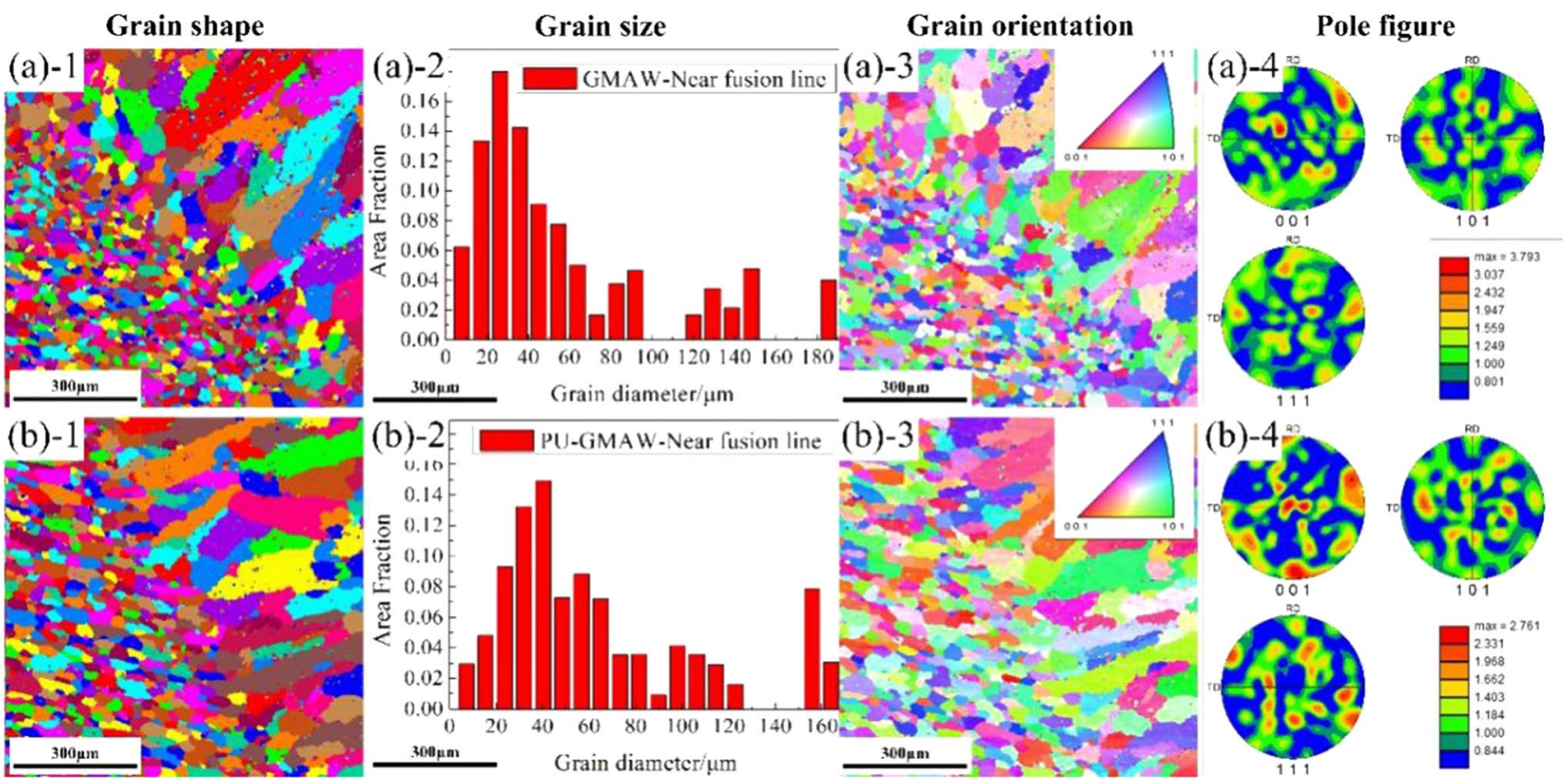

Fig. 7 Results of EBSD near the fusion line: a GMAW; b PU-GMAW
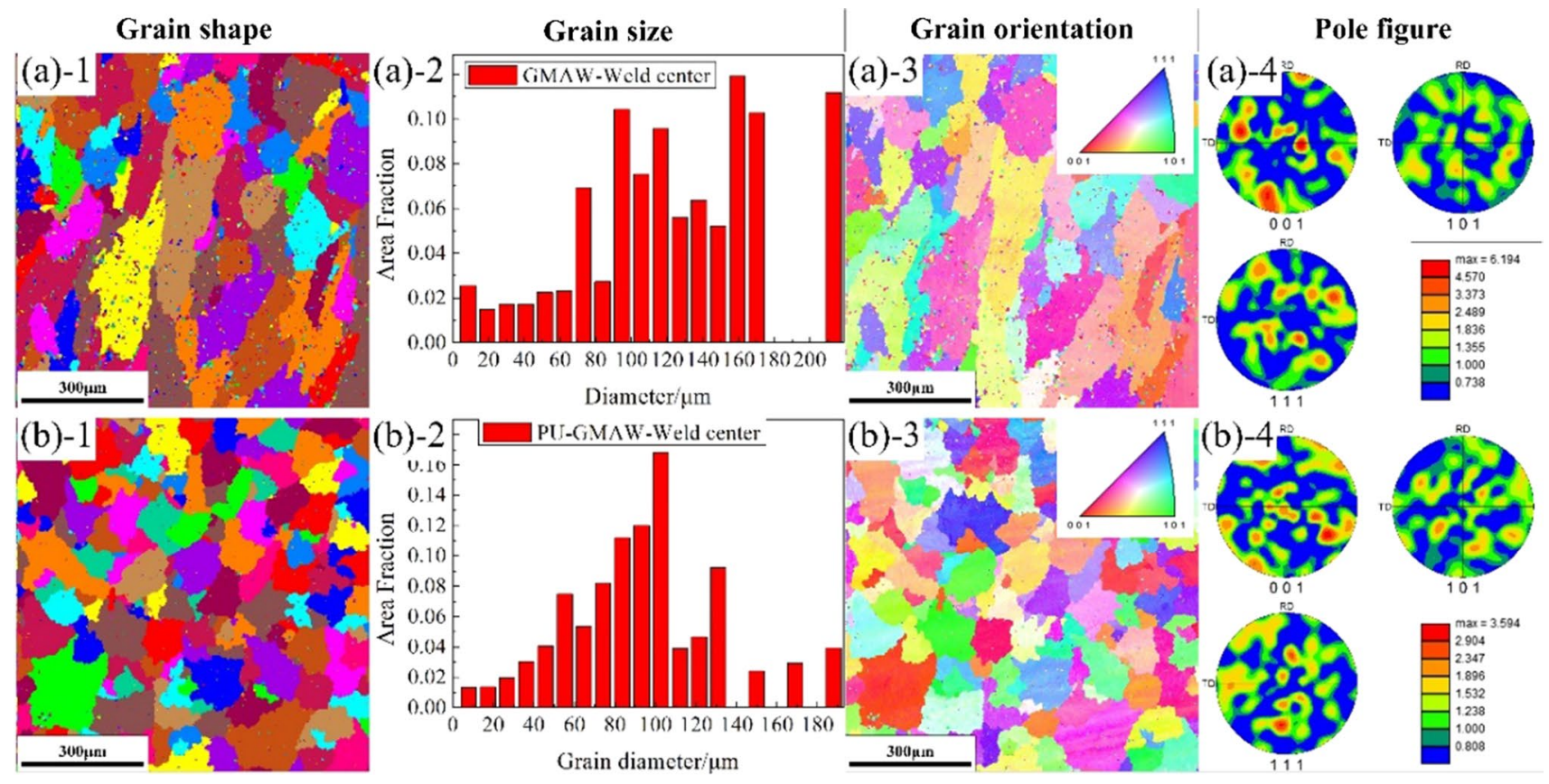

Fig. 8 Results of EBSD in the weld center: a GMAW; b PU-GMAW

of the weld pool solidification with the different welding processes.

During the PU-GMAW process, the ultrasonic was introduced into the weld pool. Dendrites were fragmented from its root by great impact force produced by the collapse of cavitation bubbles [20]. Then, the fragment dendrites were separated away from the solid-liquid interface under the action of the acoustic streaming [30]. So, more and more fragment dendrites were produced in the weld pool. The dendrite growth subjected to restriction. The refined grain was obtained in the weld bead, as shown in Fig. 8. On the other hand, the great impact force obtained by the collapse 


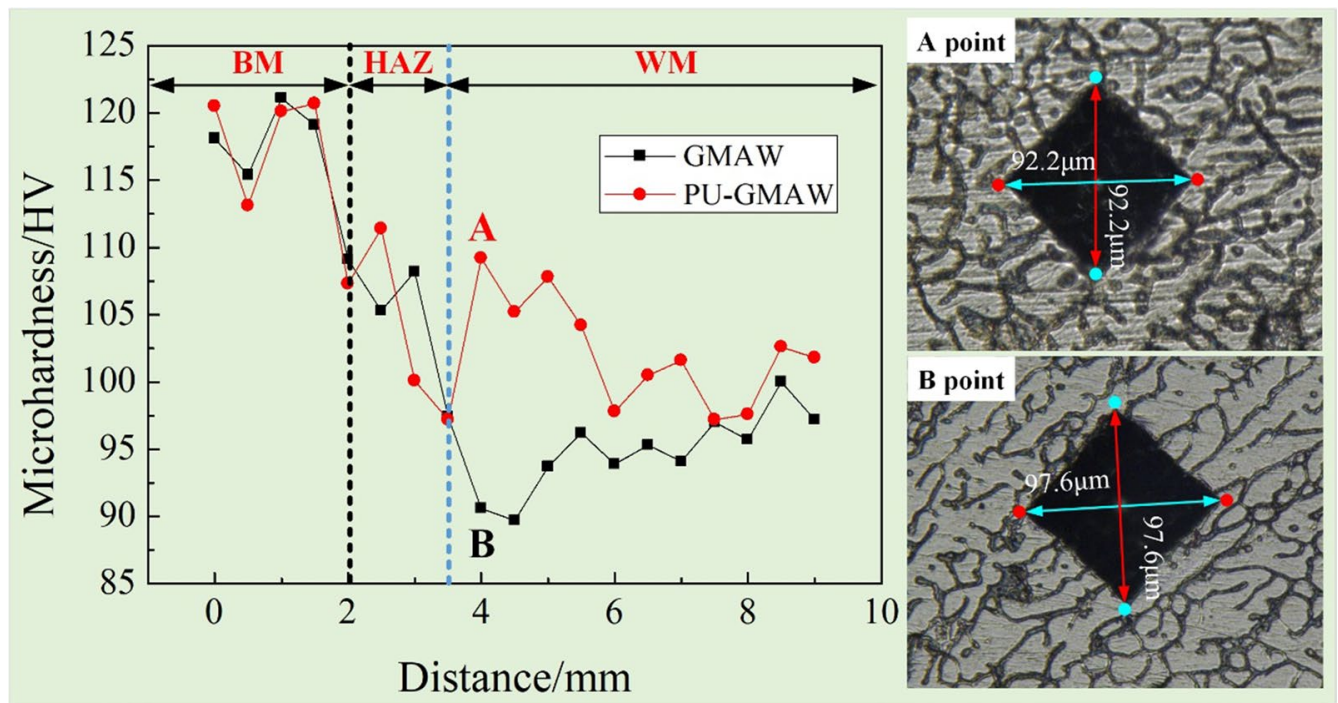

Fig. 9 Distribution of the microhardness of the weld bead

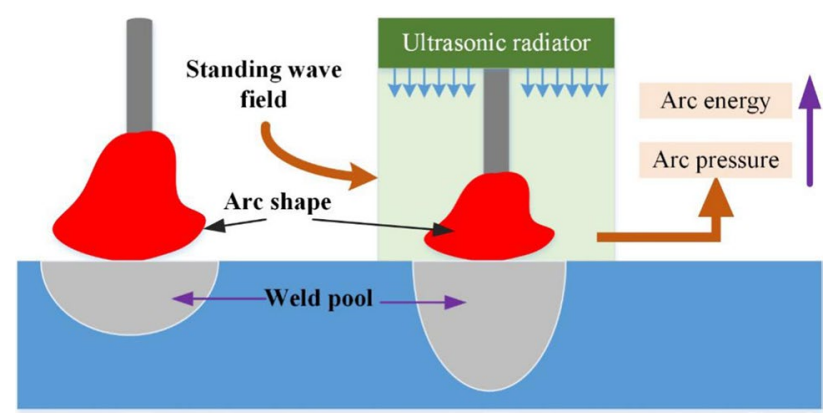

Fig. 10 Schematic illustration of the effects of the ultrasonic on the welding process of cavitation bubbles could increase the solidification temperature of the part weld pool according to the Clausius-Clapeyron equation, as follows [31].

$\frac{\mathrm{d} T}{\mathrm{~d} P}=\frac{T_{\mathrm{f}}\left(V_{\mathrm{L}}-V_{\mathrm{s}}\right)}{L_{\mathrm{f}}}$

where $T_{\mathrm{f}}$ is the equilibrium solidification temperature, $V_{\mathrm{L}}$ is the specific volume of the liquid, $V_{\mathrm{S}}$ is the specific volume of the solid, and $L_{\mathrm{f}}$ is the solidification latent heat. Therefore, the local temperature of the weld pool was less than the solidification temperature of nucleation particles. The particles were early produced in the weld pool enable to serve as potent nucleation points for $\alpha$-Al grains, which could refine the $\alpha$-Al grains.
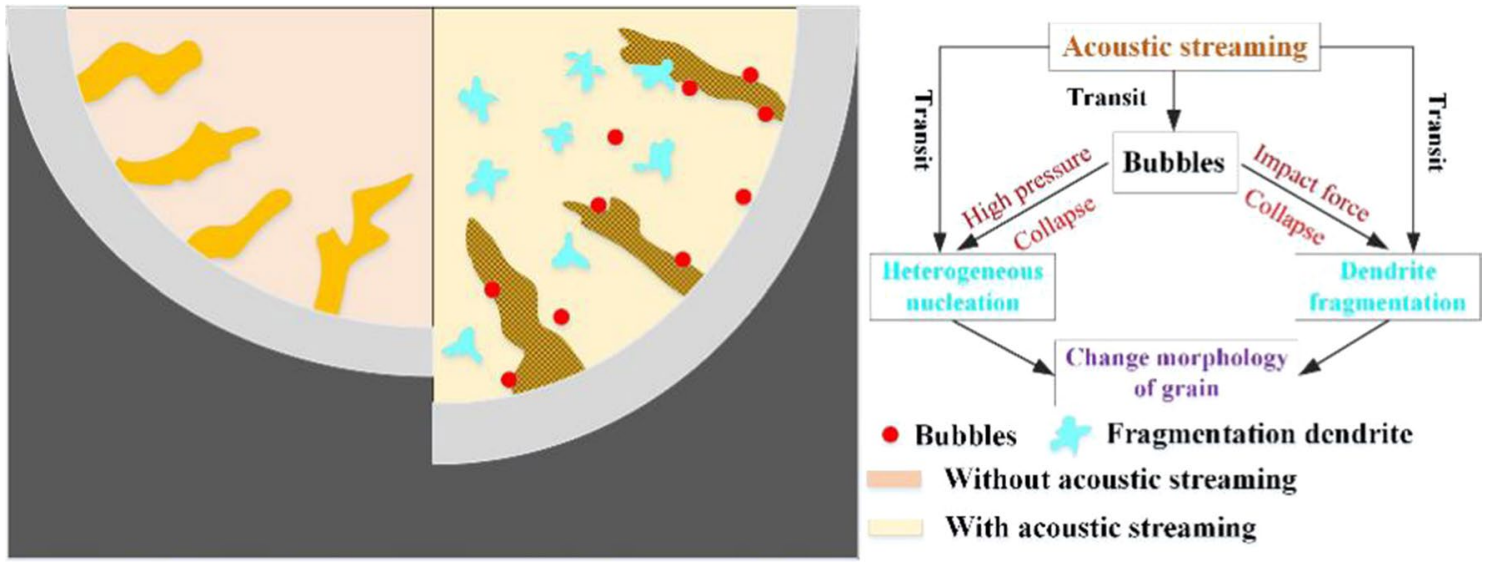

Fig. 11 Schematic illustration of the weld pool solidification 
Near the fusion line, the eutectic phase in the PU-GMAW had changed compared with that of the GMAW, as shown in Fig. 5. The phase diagram of Al-Cu is shown in Fig. 12. The temperature of the eutectic point is $548.2{ }^{\circ} \mathrm{C}$. During the equilibrium solidification, the $\mathrm{Al}-\mathrm{Cu}$ eutectic can be obtained only when the $\mathrm{Cu}$ content is 17.08 at.\%. The weld pool solidification belongs to non-equilibrium solidification [32]. The weld pool has a quick cooling rate. The liquidus will be extended with the red line, as shown in Fig. 12. Therefore, when the $\mathrm{Cu}$ content was less than 17.08 at.\%, the eutectic phase also could be obtained [33]. During the PU-GMAW, the ultrasonic was not directly applied across the eutectic transformation stage [34]. In the GMAW, the columnar crystals grew along the direction of heat dissipation (Fig. 7a). As shown in Fig. 5a, the line-like eutectic phase also grew along the direction of heat dissipation. It can be concluded that the line-like eutectic phase obtained by the GMAW was affected by the crystal morphology. In the PUGMAW, the original crystal morphology (columnar crystals) was disturbed and replaced by a hybrid crystal morphology, including columnar crystals and equiaxed grain (Fig. 7b). The growth direction of the columnar crystals was not only along the direction of heat dissipation. The coil-like eutectic phase in the PU-GMAW was obtained. The results showed that the change of the eutectic morphology was not directly affected by the ultrasound, which was indirectly affected by the change of crystal morphology.

The sequence of transformation is as following: supersaturated solid solution $\rightarrow$ GP zones $\rightarrow$ metastable $\theta^{\prime \prime}$ phase $\rightarrow$ metastable $\theta^{\prime}$-phase $\rightarrow$ stable $\theta$-phase [33]. The cavitation and acoustic streaming could not be generated in solid. During the cooling of the weld bead, the PU-GMAW weld bead was not acted by the ultrasonic. Therefore, the precipitated phase of the weld bead in the GMAW and PUGMAW has the same transformation.

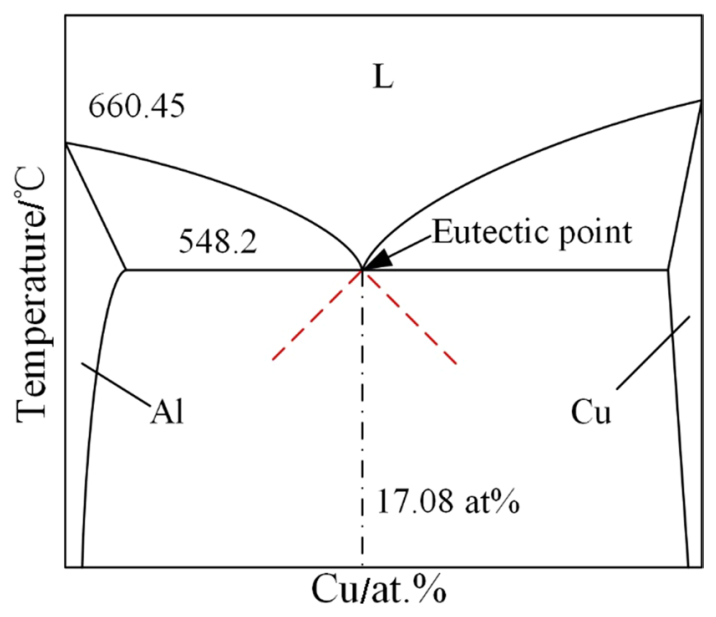

Fig. 12 Phase diagram of $\mathrm{Al}-\mathrm{Cu}$

\subsubsection{Effect of Ultrasonic on Weld Microhardness}

Refinement grain could improve the strength of materials, according to Eq. (5).

$\sigma_{\mathrm{s}}=\sigma_{0}+K d^{-\frac{1}{2}}$

where $\sigma_{\mathrm{s}}$ is the strength of materials, $\sigma_{0}$ is a constant. $K$ is the coefficient and the $d$ is the grain size. Normally, the strength of materials is directly proportional to the hardness of materials. The literature [35] indicated that the mechanical properties of aluminum alloy were affected not only by the grain size but also by the morphology of eutectic structures or precipitated phase. In the weld center, the PU-GMAW grain size was less than that of the GMAW. Therefore, the microhardness in the weld center of the PU-GMAW was greater than that of the GMAW.

Near the right side of the fusion line, the morphology of the eutectic and grain in the PU-GMAW was different from that of the GMAW. It can be concluded that the microhardness of the PU-GMAW was increased owing to the change of the eutectic and grain. From Fig. 7, the change of the grain size in the PU-GMAW was not obvious compared with that of the GMAW. The size of the eutectic phase of the PU-GMAW was reduced by 2 times compared with that of the GMAW. It can be found that the refinement eutectic phase could improve the microhardness. The coarse eutectic phase obtained by the welded joint of $\mathrm{Al}-\mathrm{Cu}$ alloy was also easy to cause hot cracks [36]. Thus, the reduction in the coarsening eutectic phase plays an important role in the improvement of mechanical properties.

\section{Conclusions}

1. The weld penetration and weld area of the PU-GMAW were increased by above 1 time compared with that of the GMAW.

2. Near the fusion line, the size of the eutectic phase of the PU-GMAW was reduced by about 2 times compared with that of the GMAW. In the weld center, the distribution and morphology of the eutectic phase of the PU-GMAW were the same with that of the GMAW.

3. Since cooling process of the weld metal was affected by ultrasonic, there is no significant difference in the distribution and morphology of precipitated phases U-GMAW and GMAW.

4. The grain size of the weld center in the PU-GMAW was reduced by about $30 \mu \mathrm{m}$ compared with that of the GMAW. 
5. The microhardness of the weld bead in the PU-GMAW was greater than that of the GMAW due to the grain and eutectic refinement.

Acknowledgements This work was also financially supported by the National Natural Science Foundation of China (No. 51675130) and the Key Program of the National Natural Science Foundation of China (No. 51435004).

\section{References}

[1] P.K. Palani, N. Murugan, J. Mater. Process. Technol. 172, 1 (2006)

[2] R. Kumar, U. Dilthey, D.K. Dwivedi, P.K. Ghosh, Mater. Des. 30, 306 (2009)

[3] S. Wei, Y. Li, J. Wang, K. Liu, Mater. Manuf. Process. 29, 954 (2014)

[4] G. Tani, G. Campana, A. Fortunato, A. Ascari, Appl. Surf. Sci. 253, 8050 (2007)

[5] F. Kong, J. Ma, R. Kovacevic, J. Mater. Process. Technol. 211, $1102(2011)$

[6] L.J. Zhang, Q.L. Bai, J. Ning, A. Wang, J.N. Yang, X.Q. Yin, J.X. Zhang, Mater. Des. 110, 35 (2016)

[7] M.M. Atabaki, J. Ma, G. Yang, R. Kovacevic, Mater. Des. 64, 573 (2014)

[8] H. Hong, Y. Han, Q. Yao, J. Tong, J. Mater. Eng. Perform. 27, $5571(2018)$

[9] H. Hong, Y. Han, M. Du, J. Tong, Int. J. Adv. Manuf. Technol. 86, 2301 (2016)

[10] J. Chen, C.S. Wu, M.A. Chen, J. Manuf. Process. 16, 485 (2014)

[11] X. Meng, G. Qin, Y. Zhang, B. Fu, Z. Zou, J. Mater. Process. Technol. 214, 2417 (2014)

[12] Y.Y. Fan, C.L. Yang, S.B. Lin, C.L. Fan, W.G. Liu, Weld. J. 91, 91s (2012)

[13] Y.Y. Fan, C.L. Fan, C.L. Yang, W.G. Liu, S.B. Lin, Sci. Technol. Weld. Join. 17, 186 (2012)
[14] C.L. Fan, W.F. Xie, C.L. Yang, S.B. Lin, Y. Fan, Metall. Mater. Trans. A 48, 4615 (2017)

[15] C. Chen, S.B. Lin, C.L. Fan, C.L. Yang, L. Zhou, Int. J. Adv. Manuf. Technol. 97, 3619 (2018)

[16] C. Chen, C.L. Fan, S.B. Lin, X.Y. Cai, C.L. Yang, L. Zhou, J. Mater. Process. Technol. 267, 376 (2019)

[17] C. Chen, C.L. Fan, X.Y. Cai, S.B. Lin, C.L. Yang, Sci. Technol. Weld. Join. 25, 20 (2020)

[18] W.L. Dai, Mater. Lett. 57, 2447 (2003)

[19] T. Yuan, S. Kou, Z. Luo, Acta Mater. 106, 144 (2016)

[20] F. Wang, I. Tzanakis, D. Eskin, J. Mi, T. Connolley, Ultrason. Sonochem. 39, 66 (2017)

[21] F. Yang, J. Zhou, R. Ding, J. Mater. Sci. Technol. 34, 2240 (2018)

[22] C. Chen, C. Fan, S. Lin, L. Zhou, C. Yang, Phys. Plasmas 25, 080703 (2018)

[23] H. Zhang, X. Zhao, D. Xu, Y. Liu, X. Qiu, Appl. Surf. Sci. 488, 115-127 (2019)

[24] H. He, Y. Yi, S. Huang, Y. Zhang, Mater. Charact. 135, 18 (2018)

[25] Q.J. Sun, S.B. Lin, C.L. Yang, G.Q. Zhao, Sci. Technol. Weld. Join. 14, 765 (2009)

[26] Y. Li, C. Wu, M. Chen, J. Phys. D Appl. Phys. 52, 035201 (2018)

[27] W.F. Xie, C.L. Fan, C.L. Yang, S.B. Lin, Ultrason. Sonochem. 29, 476 (2016)

[28] L.P. Gor'kov, In. Sov. Phys. Dokl. 6, 773 (1962)

[29] C.Y. Kong, R.C. Soar, P.M. Dickens, Mater. Sci. Eng., A 363, 99 (2003)

[30] P.J. Liew, J. Yan, T. Kuriyagawa, Int. J. Mach. Tool. Manuf. 76, $13(2014)$

[31] M.R. Ghomashchi, A. Vikhrov, J. Mater. Process. Technol. 101, 1 (2000)

[32] S. Kou, Welding metallurgy (Wiley, Hoboken, 2003), pp. 431-446

[33] Y.C. Chen, J.C. Feng, H.J. Liu, Mater. Character. 60, 476 (2009)

[34] L. Zhang, X. Li, R. Li, R. Jiang, L. Zhang, Mater. Sci. Eng., A 763, 138154 (2019)

[35] V.M.J. Sharma, K.S. Kumar, B.N. Rao, S.D. Pathak, Mater. Sci. Eng., A 502, 45 (2009)

[36] H. He, Y. Yi, S. Huang, Y. Zhang, Mater. Sci. Eng., A 712, 414 (2018) 